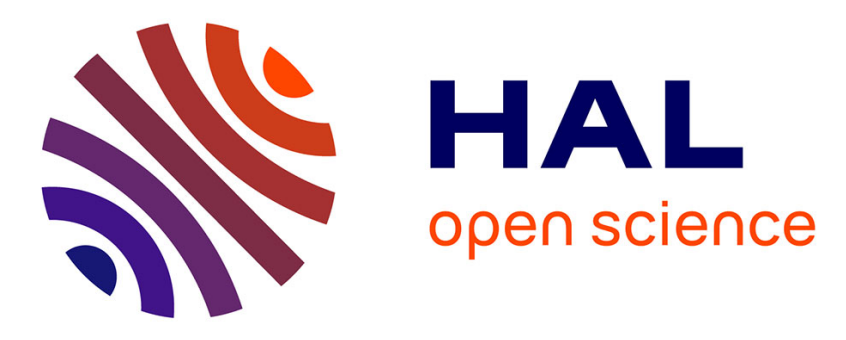

\title{
Patient-specific simulation of endovascular repair surgery with tortuous aneurysms requiring flexible stent-grafts
}

David Perrin, Pierre Badel, Laurent Orgeas, Christian Geindreau, Sabine Rolland Du Roscoat, Jean-Noël Albertini, Stéphane Avril

\section{To cite this version:}

David Perrin, Pierre Badel, Laurent Orgeas, Christian Geindreau, Sabine Rolland Du Roscoat, et al.. Patient-specific simulation of endovascular repair surgery with tortuous aneurysms requiring flexible stent-grafts. Journal of the mechanical behavior of biomedical materials, 2016, 63, pp.86-99. 10.1016/j.jmbbm.2016.06.013 . hal-01342576

\section{HAL Id: hal-01342576 https://hal.science/hal-01342576}

Submitted on 11 Jul 2016

HAL is a multi-disciplinary open access archive for the deposit and dissemination of scientific research documents, whether they are published or not. The documents may come from teaching and research institutions in France or abroad, or from public or private research centers.
L'archive ouverte pluridisciplinaire HAL, est destinée au dépôt et à la diffusion de documents scientifiques de niveau recherche, publiés ou non, émanant des établissements d'enseignement et de recherche français ou étrangers, des laboratoires publics ou privés. 


\section{Patient-specific simulation of endovascular repair surgery with tortuous aneurysms requiring flexible stent-grafts}

David PERRIN ${ }^{1,2,3,4,5}$, Pierre BADEL ${ }^{1,4,5}$, Laurent ORGEAS ${ }^{2,3}$, Christian GEINDREAU ${ }^{2,3}$, Sabine ROLLAND DU ROSCOAT $^{2,3}$, Jean-Noël ALBERTINI ${ }^{4,5,6}$, Stéphane AVRIL ${ }^{1,4,5}$

${ }^{1}$ Ecole Nationale Supérieure des Mines de Saint-Etienne, CIS-EMSE, SAINBIOSE, F-42023 Saint-Etienne, France

${ }^{2}$ CNRS, 3SR Lab, F-38000 Grenoble, France

${ }^{3}$ Univ. Grenoble Alpes, 3SR Lab, F-38000 Grenoble, France

${ }^{4}$ INSERM U1059, SAINBIOSE, F-42023 Saint-Etienne, France

${ }^{5}$ Université de Lyon, F-69000 Lyon, France

${ }^{6}$ CHU Hôpital Nord Saint-Etienne, Department of CardioVascular Surgery, Saint-Etienne F-42055, France

Corresponding author:

Stéphane Avril

Center for Biomedical and Healthcare Engineering \& SAINBIOSE INSERM U1059, Ecole Nationale Supérieure des Mines de Saint-Etienne

158 cours Fauriel, CS 62362, 42023 SAINT-ETIENNE CEDEX 2 France

Phone: +33477420188, Fax: +33477499755, Email: avril@emse.fr

Keywords: endovascular repair, abdominal aortic aneurysm, stent-graft, patient-specific, finite-element analysis 


\title{
Highlights
}

- Stent-graft samples were mechanically tested and digitised by microtomography scan.

- FE analysis was used to model stent-graft deployment in patient-specific aneurysms.

- The methodology was first evaluated by simulating in silico an in vitro deployment.

- Simulations were then compared to postoperative images for two clinical cases.

- Quantitative comparison validated simulation accuracy in tortuous anatomies.

\begin{abstract}
The rate of post-operative complications is the main drawback of endovascular repair, a technique used to treat abdominal aortic aneurysms. Complex anatomies, featuring short aortic necks and high vessel tortuosity for instance, have been proved likely prone to these complications. In this context, practitioners could benefit, at the pre-operative planning stage, from a tool able to predict the postoperative position of the stent-graft, to validate their stent-graft sizing and anticipate potential complications. In consequence, the aim of this work is to prove the ability of a numerical simulation methodology to reproduce accurately the shapes of stent-grafts, with a challenging design, deployed inside tortuous aortic aneurysms. Stent-graft module samples were scanned by X-ray microtomography and subjected to mechanical tests to generate finite-element models. One EVAR clinical case was numerically reproduced by simulating stent-graft models deployment inside the tortuous arterial model generated from patient pre-operative scan. In the same manner, an in vitro stent-graft deployment in a rigid polymer phantom, generated by extracting the arterial geometry from the pre-operative scan of a patient, was simulated to assess the influence of biomechanical environment unknowns in the in vivo case. Results were validated by comparing stents positions on simulations and post-operative scans. In both in vivo and in vitro cases, simulation accurately predicted stents deployed locations and shapes (11.8 and $4.1 \mathrm{~mm}$ maximum position error along vessel centerline for stents of the in vivo and in vitro cases respectively). The good results obtained in the in vitro case validated the ability of the methodology to simulate stent-graft deployment in very tortuous arteries and led to think proper modelling of biomechanical environment could reduce the few local discrepancies found in the in vivo case. In conclusion, this study proved that our methodology can achieve accurate simulation of stentgraft deployed shape even in tortuous patient specific aortic aneurysms and may be potentially helpful to help practitioners plan their intervention.
\end{abstract}




\section{Introduction}

Abdominal aortic aneurysm (AAA) is an asymptomatic disease which consists in an abnormal enlargement of the aorta. Some criteria, like aneurysm diameter (Conway et al., 2001) or peak wall stress (Fillinger et al., 2003), were developed to assess the growth of the aneurysm and its risk of rupture. Once a criterion is met, two surgical procedures can be undertaken to prevent aneurysm rupture: (i) conventional open repair where the aneurysm is replaced by a prosthesis or (ii) endovascular repair (EVAR) where a stent-graft (SG) is deployed inside the aneurysm sac to exclude the AAA from blood flow. The latter is less invasive for patients; however it involves higher risk of secondary intervention (Greenhalgh et al., 2010): complications like endoleaks or thrombosis may arise, especially in case of patients presenting challenging arterial anatomies with tortuous vessels. Aortic neck angulation is a strong factor of adverse surgery outcomes (Aburahma et al., 2011; Albertini et al., 2006; Sternbergh et al., 2002). Iliac tortuosity has been proven to correlate with occlusion likelihood (Cochennec et al., 2007). In case of such anatomical difficulties, finite-element (FE) analysis could be used to anticipate complications, providing a chance for practitioners to prevent them. In addition, EVAR could therefore become more prevalent by treating patients who would have been excluded from EVAR technique without information provided by FE analysis.

In order to achieve the prediction of EVAR outcomes, SG deployment must be simulated in patientspecific AAAs, with good accuracy even in complex anatomies that are more prone to complications. Research on this topic started more than 5 years ago with the development of the first FE models for SGs (Demanget et al., 2012b; Kleinstreuer et al., 2008). The mechanical behaviour of bifurcated SGs was first modelled only 2 years ago (De Bock et al., 2013). Afterwards, these models were used to feed FE simulations of SG deployment. About SG deployment, we can cite limb deployment in idealised vessels (Perrin et al., 2015b), simulation of in vitro SG main body deployment (De Bock et al., 2012) and patientspecific aortic endografting (Auricchio et al., 2013). Our group also recently managed to simulate the deployment of aorto-bi-iliac SGs in patient-specific AAAs (Perrin et al., 2015a). However, all the aforementioned studies only dealt with rather simple arterial geometries: idealised tubular shapes, idealised fusiform AAA, short patient-specific ascending aorta or rather straight patient-specific AAAs. FE simulation has not yet been performed on complex clinical cases featuring pronounced tortuosity where loading and constraints exerted onto the SG are complex and challenging for practitioners to anticipate. Moreover, only the deployment of SGs with Z-shaped stents was simulated. Frequently in tortuous anatomies other SGs may be used, with stent designs providing more flexibility. To be able to simulate 
numerically such complex procedures, these SG designs had yet to be modelled and the numerical challenges induced by their flexibility still had to be overcome.

In this study, our objectives were threefold:

1. To develop a computational model able to predict the deployment of highly flexible SGs (Anaconda ${ }^{\mathrm{TM}}$ from the Vascutek company - a Terumo company, Inchinnan, UK) in the aneurysm of any patient.

2. To estimate the reliability and accuracy of this computational model with respect to a reference experiment. For this, the aneurysm of a patient was replicated as a rigid polymer phantom and a real SG was experimentally deployed in it. The position of the deployed SG was digitised using a high resolution laboratory X-ray microtomograph and compared to the numerical predictions.

3. To make the proof of concept that the computational model can predict accurately the SG placement in patients during EVAR procedures. For this, the position of the deployed SG in two patients was measured using images of the post-operative CT scan and compared to the numerical predictions.

\section{Material and methods}

\subsection{AAA modelling}

\subsubsection{Clinical review}

Three patients were chosen in the clinical database after informed consent and approval from the Institutional Review Board. They presented anatomic features which were severe enough to require the deployment of a highly flexible SG. Commonly accepted parameters indicating the complexity of arterial anatomies are reported for these three cases in Table 1. Low value of angulation $\left(<130^{\circ}\right)$ indicates vessel tortuosity, which may complicate pre-operative SG sizing and induce poor stent apposition against the arterial wall or SG kinking. Short aortic neck length $(<15 \mathrm{~mm})$ is an additional difficulty for surgeons to manage good SG support and sealing of the proximal SG extremity. 


\begin{tabular}{|c|c|c|c|}
\hline & Case 1 (in vitro) & Case 2 (in vivo) & Case 3 (in vivo) \\
\hline $\begin{array}{l}\text { Aortic neck : } \\
\text { Length } \\
\text { Angulation } \\
\text { Other }\end{array}$ & $\begin{array}{c}10 \mathrm{~mm} \\
130^{\circ}\end{array}$ & $\begin{array}{c}15 \mathrm{~mm} \\
120^{\circ}\end{array}$ & $\begin{array}{c}\text { Suprarenal } \\
\text { aneurysm }\end{array}$ \\
\hline $\begin{array}{l}\text { Right iliac: } \\
\text { Angulation } \\
\text { Other }\end{array}$ & $\begin{array}{c}130^{\circ} \\
\text { Iliac aneurysm, } \\
30 \mathrm{~mm} \\
\text { diameter, with } \\
\text { diameter } \\
\text { reduction down } \\
\text { to } 8 \mathrm{~mm}\end{array}$ & $\begin{array}{c}90^{\circ} \\
\text { Iliac aneurysm, } 40 \\
\text { mm diameter }\end{array}$ & $\begin{array}{c}110^{\circ} \\
\text { Iliac aneurysm, } 23 \\
\text { mm diameter }\end{array}$ \\
\hline $\begin{array}{l}\text { Left iliac: } \\
\text { Angulation } \\
\text { Other }\end{array}$ & $110^{\circ}$ & $\begin{array}{c}110^{\circ} \\
\text { Iliac aneurysm, } 20 \\
\text { mm diameter }\end{array}$ & $\begin{array}{c}100^{\circ} \\
\text { Iliac aneurysm, } 25 \\
\text { mm diameter }\end{array}$ \\
\hline
\end{tabular}

Table 1. Commonly accepted parameters indicating the complexity of arterial anatomies for the three cases.

For the first patient, only the pre-operative CTA scan was available. It permitted to create a stereolithography file of his aneurysm's geometry, which was used to make a polymer phantom by 3D printing (case 1). This allowed to obtain a well-controlled reference experiment (involving imaging the deployed SG with a laboratory X-ray microtomograph having a higher spatial resolution than medical CTA) for verifying the computational model before using it for the prediction of SG deployment in real cases. This patient was selected for the following reasons:

1. His vessels were pronouncedly tortuous, which made him be eligible for an Anaconda ${ }^{\mathrm{TM}} \mathrm{SG}$ (see details in Table 2).

2. For reasons independent to this study, another SG was finally used during his EVAR procedure, so the Anaconda ${ }^{\mathrm{TM}}$ SG that had been specifically sized for this patient by an experienced surgeon was incidentally available for an in vitro experiment.

3. The diameter of his iliac arteries was large enough and still straight enough, permitting the introduction and deployment of the SG even inside a rigid polymer phantom, despite the lack of compliance of the rigid phantom compared to actual iliac arteries. 


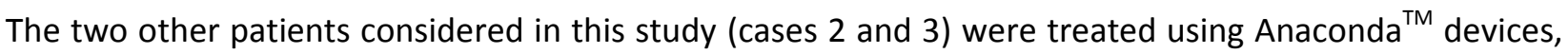
the references of which are reported in Table 2 . In both cases, the pre-operative and post-operative CTA scans were available for our study.

\begin{tabular}{|c|c|c|c|}
\hline & Case 1 (in vitro) & Case 2 (in vivo) & Case 3 (in vivo) \\
\hline Main body & One Lok OLB30 & One Lok OLB30 & One Lok OLB34 \\
\hline Right iliac limbs & Straight limb L12X100 & Straight limb L12X120 & Straight limb L12X140 \\
& Flared limb FL1215X130 & Straight limb L12X100 & Straight limb L12X80 \\
& & Flared limb FL1215X130 & \\
\hline Left iliac limbs & Straight limb L12X140 & Straight limb L12X140 & Straight limb L12X140 \\
& & Flared limb FL1223X90 & Straight limb L12X60 \\
\hline
\end{tabular}

Table 2. Device summary (SG modules) for the three cases.

\subsubsection{Case 1 (in vitro)}

The pre-operative CTA scan of the first patient was used to manufacture a rigid phantom. The voxel size of the CTA scan was $0.773 \times 0.773 \times 1.0 \mathrm{~mm}^{3}$.

The arterial lumen geometry was extracted with surgery oriented Endosize ${ }^{\circledR}$ software (Therenva, France) as shown in Figure $1 \mathrm{~A}$ and meshed with triangular shell elements (1.5 $\mathrm{mm}$ mean edge length) as illustrated in Figure 1B, following the methodology detailed in (Perrin et al., 2015a). These elements were not assigned mechanical properties as they represented the inner surface of the rigid phantom made of a thermoset polymer, assumed to have negligible deformations induced by the SG. This phantom (Figure 1C) was manufactured by 3D printing, using ZBuilder printer (3DSYSTEMS, Rock Hill, SC, USA). SG deployment was performed by an experienced vascular surgeon, as in clinical routine. Guidewires were inserted through each iliac artery. SG modules, listed in Table 2, were deployed successively by inserting the delivery system and then removing the sheath, as indicated in Instructions For Use (IFU). Since the polymer of the phantom was opaque, to be as close as possible to the actual surgery, the procedure was monitored with standard intraoperative two-dimensional fluoroscopy. 


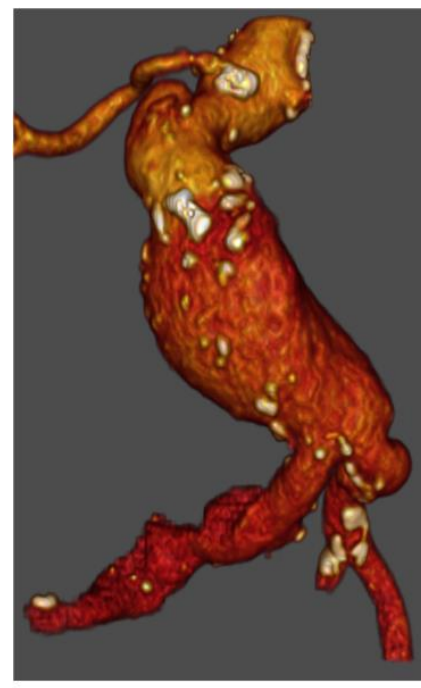

A

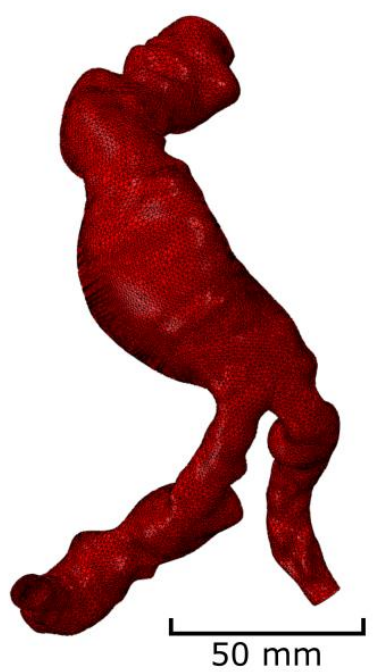

B

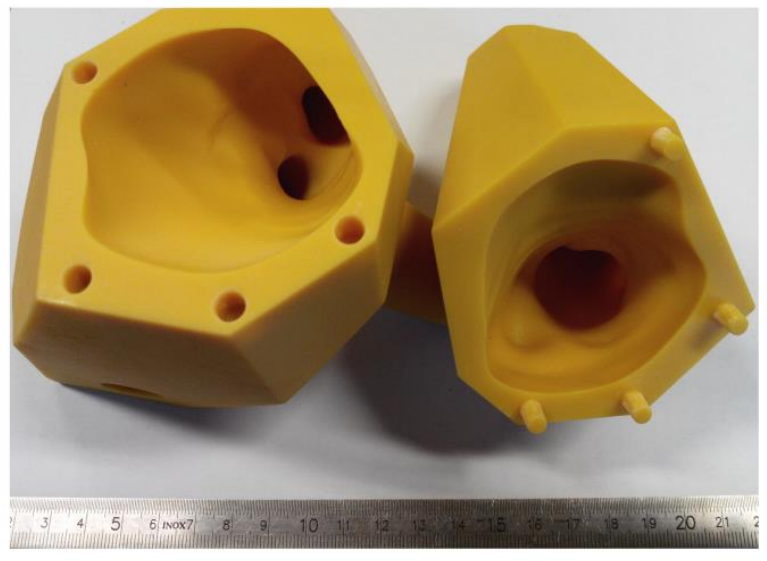

C

Figure 1. Vessel geometry of the patient of case 1 (in vitro): pre-operative scan (A), FE mesh of the preoperative lumen surface $(B)$ and two connected parts of the rigid polymer phantom manufactured by 3D printing of the FE geometry (C).

Deployed SG shape was digitised by scanning the phantom and the SG inside in an X-ray microtomograph, at 3SR Lab (Grenoble, France). 3D image resolution was $97 \times 97 \times 97 \mu^{3}$. The scan was rigidly registered to the FE model by matching ten landmarks picked in both of them using iterative closest point method, implemented in Matlab (The MathWorks, Inc., Natick, MA, USA). Resulting registration error was $0.8 \pm 0.3 \mathrm{~mm}$. Stent positions on the microtomography scan were chosen as references for simulation assessment. They were segmented by standard thresholding operation. Their neutral axes were then computed by skeletonisation using BoneJ (Doube et al., 2010), a plugin of ImageJ. The recorded 3D image was clean enough to properly distinguish each stent, all of them thus included in the simulation assessment.

\subsubsection{Cases 2 and 3 (in vivo)}

Pre-operative and post-operative CTA scans of case 2 (resp. case 3) had respective voxel sizes of $0.763 \mathrm{x}$ $0.763 \times 0.625 \mathrm{~mm}^{3}$ (resp. $0.63 \times 0.63 \times 0.63 \mathrm{~mm}^{3}$ ) and $0.828 \times 0.828 \times 0.7 \mathrm{~mm}^{3}$ (resp. $0.96 \times 0.96 \times 0.7$ $\mathrm{mm}^{3}$ ) (Figure 2). They were set in the same coordinate system after rigid registration. For this purpose, ten anatomical landmarks located on patient bones and vertebras (i.e. fixed points) were picked on both scans. The iterative closest point method was used to find the best transformation to match datasets and register pre and post-operative scans. Uncertainties due to differences in patient positioning and point picking led to $1.2 \pm 0.6 \mathrm{~mm}$ (resp. $0.8 \pm 0.3 \mathrm{~mm}$ ) mean position error between registered datasets. 
The geometry of the arterial lumen was digitised from the pre-operative scan using Endosize ${ }^{\circledR}$ software. The methodology proposed in (Perrin et al., 2015a) was used to generate the mesh and to model the mechanical behaviour of arterial walls. More specifically, they were modelled by triangular shell finiteelements (1.5 mm mean edge length), $1.5 \mathrm{~mm}$ or $1 \mathrm{~mm}$ thick in aortic or iliac areas. The corresponding mesh is shown in Figure 2B. Elements were assigned orthotropic linear elastic material properties. The constitutive parameters, computed by a linearization of the Holzapfel-Gasser-Ogden hyperelastic law (Gasser et al., 2006) in physiological conditions, as in (Perrin et al., 2015a), are reported in Table 3.

Stent positions on the post-operative CTA scan were chosen as reference positions to verify our deployment simulation. Stents were segmented on scan images with a region growing algorithm. Their centrelines were computed by a 3D skeletonisation algorithm in ImageJ (Lee et al., 1994). Note that some stents could not be properly segmented because of calcifications, stent overlapping and the low spatial resolution. They were excluded from the simulation assessment. 

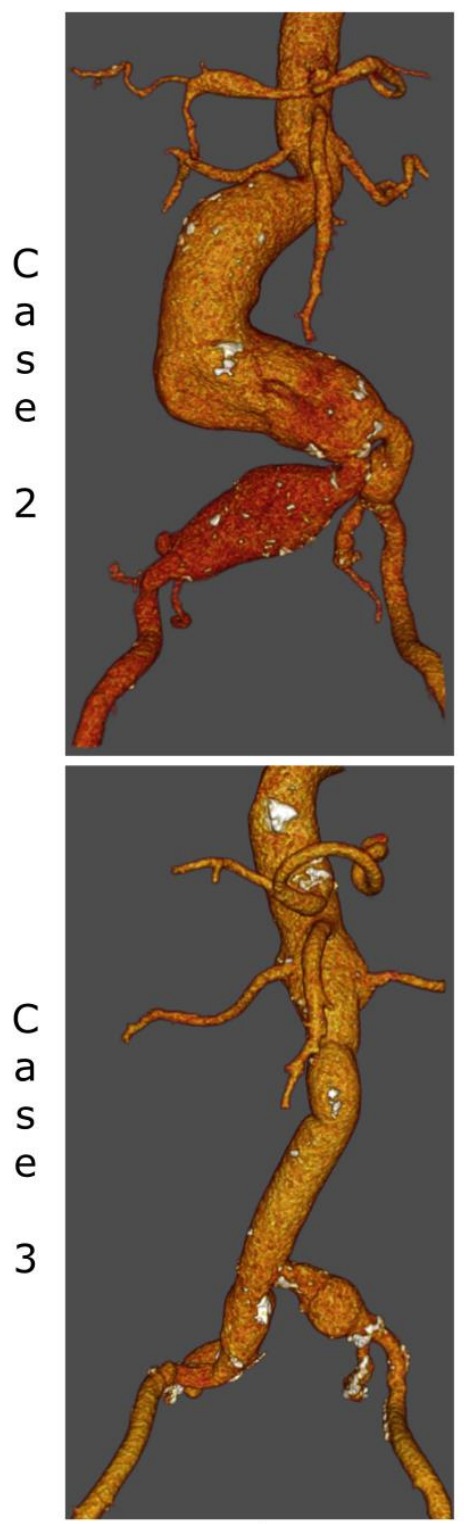

A
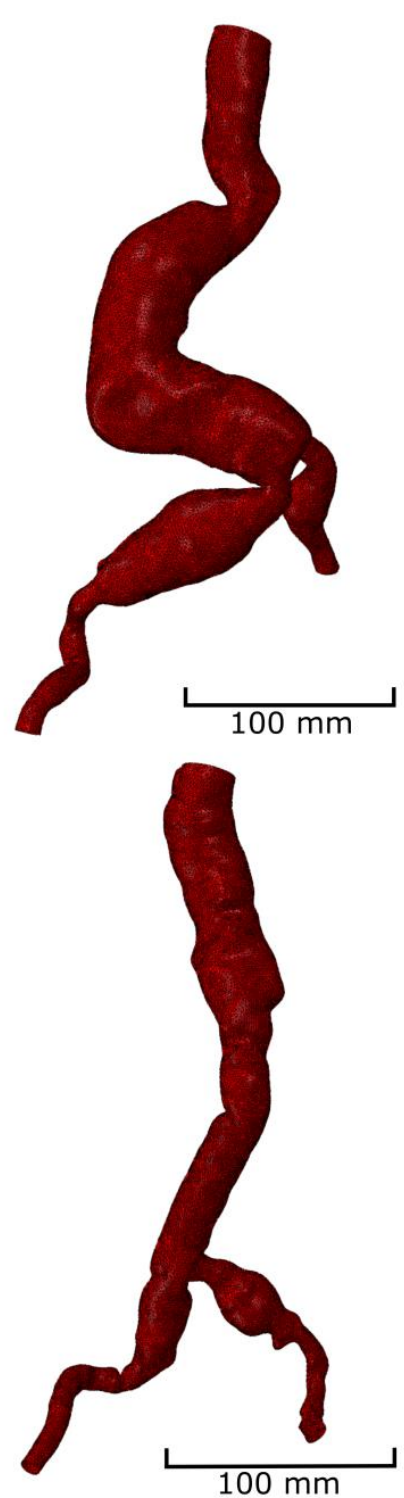

B
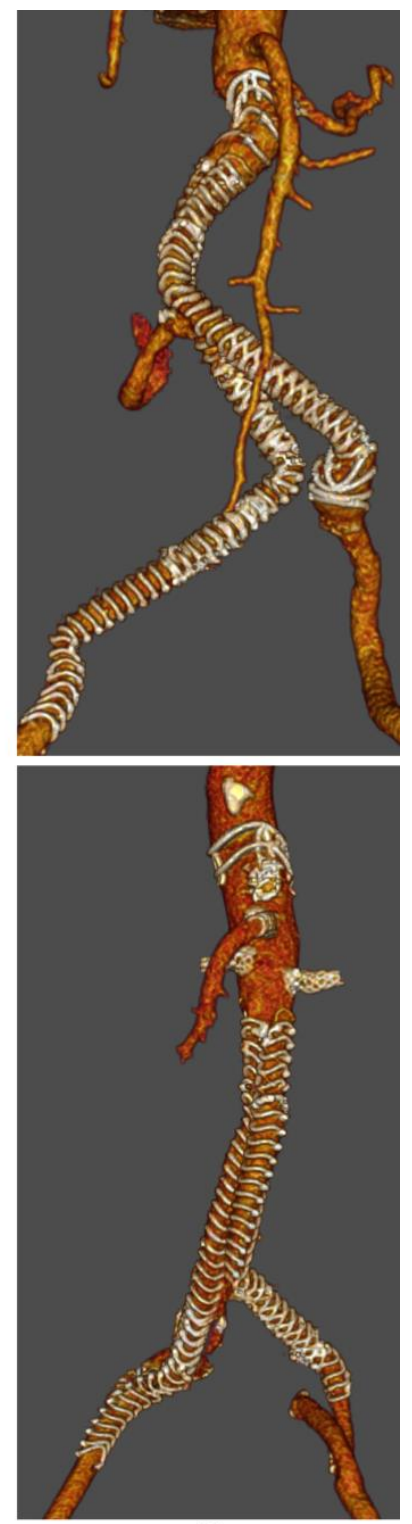

C

Figure 2. Vessel geometries of cases 2 and 3 (in vivo): pre-operative scans (A), FE meshes of the preoperative lumen surface (B) and post-operative scans (C).

\begin{tabular}{|c|c|c|}
\hline$E_{z}(\mathrm{MPa})$ & Longitudinal elastic modulus & 3.58 \\
\hline $\mathrm{E}_{\theta}(\mathrm{MPa})$ & Circumferential elastic modulus & 1.11 \\
\hline $\mathrm{V}_{\theta z}$ & In-plane minor Poisson ratio & 0.44 \\
\hline $\mathrm{G}_{z \theta}(\mathrm{MPa})$ & In-plane shear modulus & 4.0 \\
\hline
\end{tabular}

Table 3. In-plane material parameters of the linearized orthotropic elastic model of the arterial wall. 


\subsection{Stent-graft modelling}

Anaconda ${ }^{\mathrm{TM}}$ modules (Figure $3 \mathrm{~A}$ ) are composed of a graft and several stents having a complex design that required careful analysis. Indeed, stents are made of a thin Nitinol wire wrapped several times (from 4 to 14 times depending on the stent) around the graft (Figure 3B). From an initial circular shape, stents take a saddle shape when tied onto the graft, thanks to sutures whose positions along the SG axis are varying as a sinusoid (Figure $3 \mathrm{C}$ ).

Therefore, to model Anaconda ${ }^{\mathrm{TM}}$ SGs, spare samples of each module presented in Table 2 were experimentally tested for model calibration.

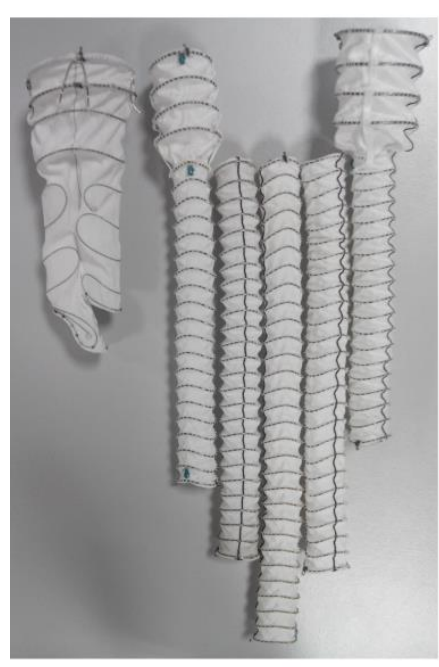

A

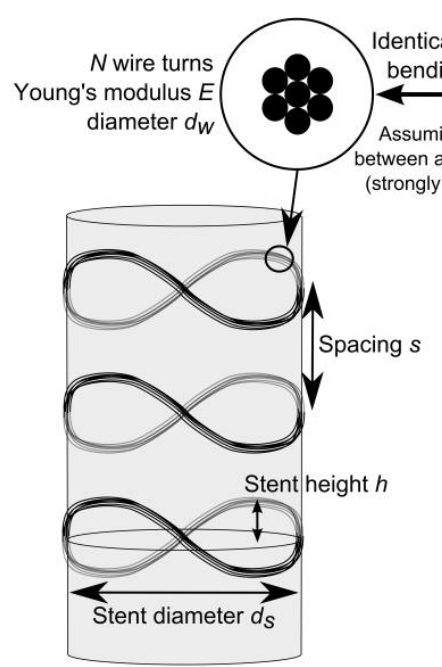

B
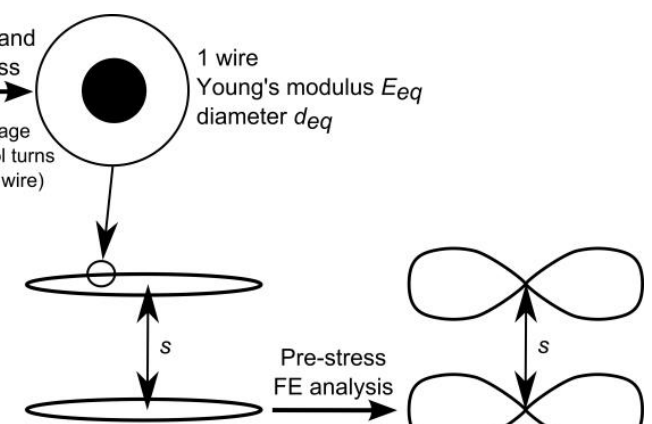

$s$

Imposed longitudinal displacement on nodes

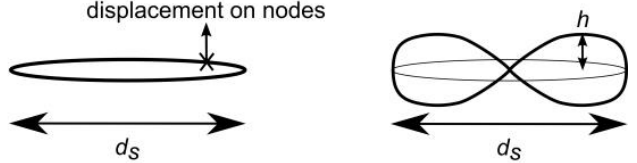

C

Figure 3. SG modules (one main body and five iliac limbs) tested for model calibration (A), schematic of stent saddle shape (B), stress free and pre-stressed geometries of the FE beam model of the stents (C).

\subsubsection{X-ray microtomography}

All the modules were scanned in the X-ray microtomograph at the 3SR lab. An experimental setup was used to maintain them vertically. Sliding connection allowed adjusting the distance between module extremities. Therefore, devices could be scanned in two relevant configurations: (i) stretched, when the textile did not present any wrinkles between stents (Figure 4A) and (ii) relaxed, without prescribing any tension (Figure 4B). The first configuration was used to pre-stress the stents and tie them properly onto the graft, in the saddle shape. The second configuration was used to verify the stent model by comparing FE predictions of the load-free state with scan images. The 3D image resolution obtained by microtomography ranged from $48 \times 48 \times 48 \mu^{3}$ to $95 \times 95 \times 95 \mu^{3}$, depending on device length. As described for case 1, stents were segmented by thresholding and their neutral axes were extracted by skeletonisation (Figure 4C). 


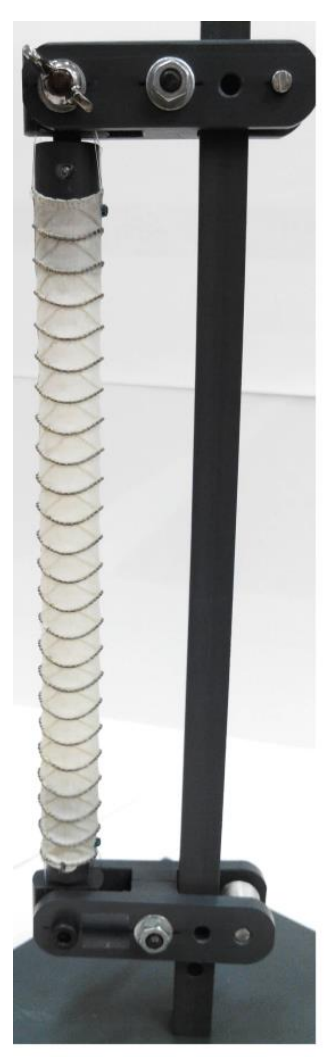

A

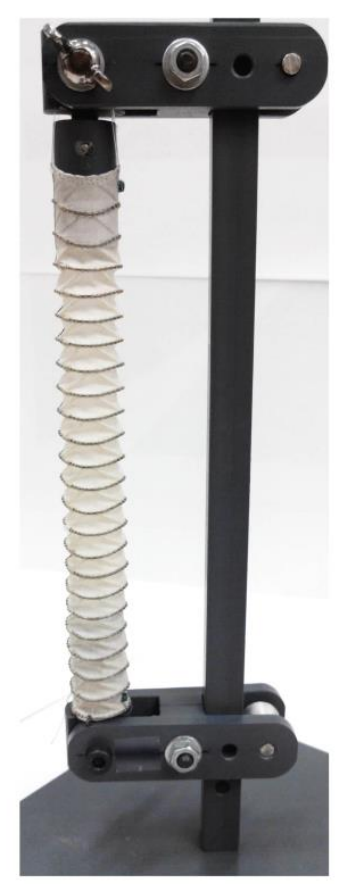

B

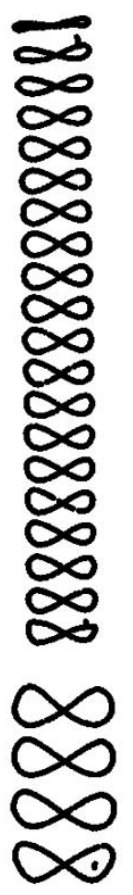

C

Figure 4. Experimental setup inserted in the microtomograph to derive the geometry of SG modules in stretched (A) and tension-free (B) states. Example of stent neutral axes extracted from microtomography scan images (C).

\subsubsection{Stent modelling}

Mechanical properties of Nitinol were first characterised by uniaxial tensile tests on single stent wires collected from SG samples. To avoid slippage in grips due to the very small thickness of wires, wires were tied to make a knot. Two jaws were then inserted inside the loop of the knot and kinematically driven by the tensile machine (Instron, Norwood, MA, USA), equipped with a $50 \mathrm{~N}$ load cell. Tensile tests were carried out at low strain rate, i.e. $10^{-4} \mathrm{~s}^{-1}$, to minimise thermomechanical coupling effects (Churchill et al., 2009). A rather weak scattering was recorded for stress-strain curves. This could be ascribed to the variability induced by the manufacturing process, as also observed by Henderson et al. (2011). Nitinol was modelled as a linear elastic material, with a Young's modulus of $40 \mathrm{GPa}$ according to measured austenitic modulus and Poisson's ratio of 0.3 . This simplification was undertaken as preliminary results showed that Nitinol remained in its austenitic phase during SG deployment simulations, since they used a methodology that did not need to model the full crimping of the SG inside its delivery sheath. 
Stents were first assumed as perfect circles, their diameters $d_{s}$ were set equal to the average diameter of similar stents measured on the microtomography scans in stretched state. They were meshed with linear beam elements $(0.25 \mathrm{~mm}$ length) to reduce simulation time without losing accuracy (Hall and Kasper, 2006). To compute their pre-stressed state afterwards, they were deformed in a preliminary FE analysis to give them a proper saddle shape (Figure 3 C). Nodes were assigned proper displacements along SG axis, to reach stent height $h$ corresponding to the scan in stretched state. As all FE simulations of this study, this analysis was performed with the explicit solver of Abaqus software (Simulia, Dassault Systems, Providence, RI, USA).

In the FE model, the several turns of Nitinol wires that constitute a stent were represented by a single equivalent beam having a circular cross section. To assign the same bending stiffness to the beam as the several turns of wires, an equivalent radius was derived (Figure 3C). As a consequence, the Young's modulus was also adjusted to keep the same tensile stiffness. The values of the tensile stiffness and bending stiffness depending on the stent and its number of wire are expressed in Table 4, as well as the parameters of the beam elements representing these different stents. To verify this model, the following FE analysis was performed: the extremities of SG modules were released to let them free to deform until their relaxed static mechanical equilibrium was reached (Figure 5C). Shapes and positions of their stents could then be compared with those acquired with X-ray microtomography, in both stretched and relaxed configurations (Figure 5D). We found a good agreement between FE models and experiments, which validated stent modelling.

\begin{tabular}{|c|c|c|c|c|c|}
\hline $\begin{array}{c}\text { Stent diameter } \\
(\mathrm{mm})\end{array}$ & $\begin{array}{c}\text { Turns of } \\
\text { Nitinol wire }\end{array}$ & $\begin{array}{c}\text { Tensile } \\
\text { stiffness }(\mathrm{kN})\end{array}$ & $\begin{array}{c}\text { Bending } \\
\text { stiffness } \\
\left(\mathrm{N} . \mathrm{mm}^{2}\right)\end{array}$ & $\begin{array}{c}\text { Radius of beam } \\
\text { elements }(\mathrm{mm})\end{array}$ & $\begin{array}{c}\text { Young's modulus } \\
\text { of beam elements } \\
(\mathrm{GPa})\end{array}$ \\
\hline 34 & 11 & 17.65 & 394 & 0.30 & 62.9 \\
\hline 30 & 11 & 17.65 & 394 & 0.30 & 62.9 \\
\hline 28 & 6 & 9.63 & 133 & 0.24 & 55.4 \\
\hline 25 & 4 & 3.22 & 15 & 0.14 & 53.3 \\
\hline 23 & 14 & 11.26 & 144 & 0.23 & 60.0 \\
\hline 15 & 11 & 7.57 & 73 & 0.20 & 55.7 \\
\hline 12 & 8 & 3.62 & 19 & 0.14 & 62.9 \\
\hline
\end{tabular}

Table 4. Radius of the circular cross-section and Young's modulus of the beam elements to exhibit the same tensile stiffness and bending stiffness as the actual stents. 


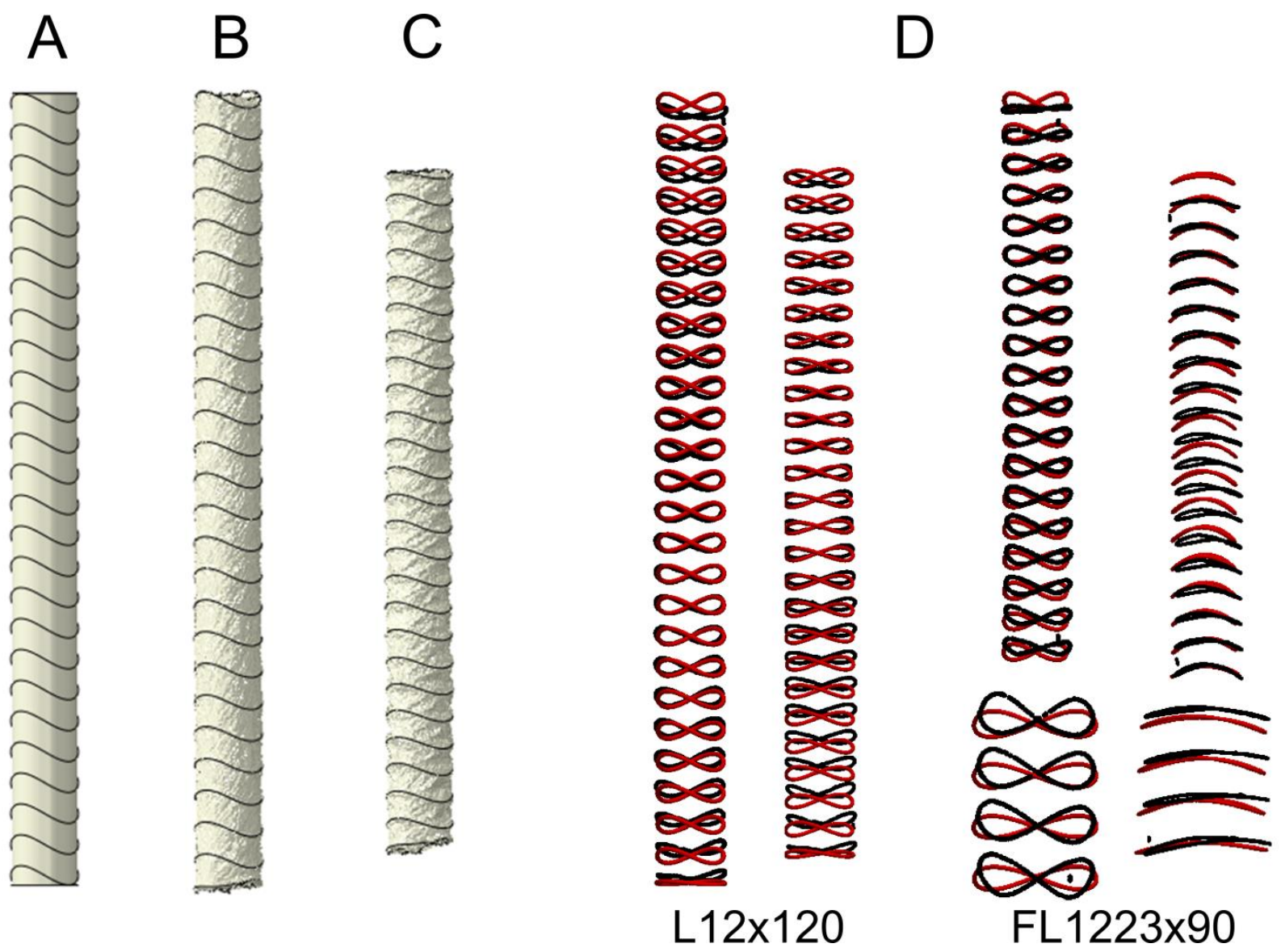

Figure 5. Deformed geometries of an iliac limb before tying the stents to the graft (A), after activating the tie constraint in stretched (B) and tension-free (C) states. Qualitative validation of the FE models of two limbs (a straight one and a flared one) by comparing FE predictions (red) to the actual position of the stents derived from microtomography (black) in stretched and tension-free configurations (D).

Two actual stents, located at the main body stumps, were not circular. Their complex shape added some difficulty to generate an ideal geometry or to input directly neutral axes from microtomography into the FE model. Given their marginal impact onto the mechanical behaviour of the SG (relatively thin diameters), these stents were not modelled.

\subsubsection{Graft modelling}

The textile parts of the limbs were modelled as circular tubes with diameters equal to the inner diameters of the stents. Graft geometries were then meshed with 4-node shell elements $(0.35 \mathrm{~mm}$ mean edge length). The textile was modelled as a linear elastic orthotropic material. Its constitutive parameters and thickness (Table 5) were determined after in-house experimental tests, to match experimental in-plane and bending stiffness reported in (Demanget et al., 2012a). 
The geometry of the SG main body was generated using computer assisted design software Inventor (Autodesk Inc., San Rafael, CA, USA). Above the bifurcation, the graft diameter was defined as equal to the inner diameter of the stents. Bifurcation and stumps were designed according to the dimensions reported in the Anaconda ${ }^{\mathrm{TM}}$ documentation.

\begin{tabular}{|c|c|c|}
\hline$t(\mathrm{~mm})$ & Adjusted element thickness & 0.02 \\
\hline$E_{z}(\mathrm{GPa})$ & Longitudinal elastic modulus & 1.125 \\
\hline $\mathrm{E}_{\theta}(\mathrm{GPa})$ & Circumferential elastic modulus & 5.0 \\
\hline$v_{\theta z}$ & In-plane minor Poisson ratio & 0.2 \\
\hline $\mathrm{G}_{z \theta}(\mathrm{GPa})$ & In-plane shear modulus & 18.0 \\
\hline
\end{tabular}

Table 5. In-plane material parameters of the orthotropic elastic model of the textile.

\subsubsection{Modules assembly}

Each SG module was assembled by putting together the textiles and the pre-stressed stents (Figure 5A). The pre-stressed state of each module in its stretched state was then computed by activating the kinematical constraint (i.e. tie) between the stents and the graft, while maintaining its length constant by fixing its extremities (Figure 5B).

\subsection{Simulation methodology of SG deployment}

We have previously developed a specific methodology to simulate SG deployment (Perrin et al., 2015a). We explain hereafter how the methodology was extended to the Anaconda ${ }^{\mathrm{TM}}$ SG.

\subsubsection{Crimping and assembly}

For all deployment simulations, SG modules were registered in the same configuration as the one of the actual cases. Since all SG modules are deployed simultaneously in our simulations, they had to be inserted one inside another as they are at the end of the intervention. This required a preliminary FE simulation which consisted in crimping the distal modules and in inserting them inside the proximal modules. Crimping was achieved by surrounding SG modules by inside and outside cylinders having appropriate diameter. This was achieved in the stretched state to mimic SG axial stretching occurring when SGs are actually pulled into their deployment sheath. At the end of the crimping simulations, extremities were released to compute the final equilibrium of the devices in their sheaths. Examples of this simulation are shown in Figure 6A.

After the crimping stage, SG modules were assembled together by adjusting their respective position to reproduce actual overlap lengths. The measurement of these actual overlap lengths was based on 
distances between radio-opaque markers observed on the microtomography or CTA scans. Resulting SG assembly is shown in Figure 6B.

\subsubsection{SG wrapping}

A tubular shell, wrapping the assembled SG, was generated according to the procedure described in (Perrin et al., 2015a). Briefly, vessel centrelines and splines describing patient arterial lumen were extracted from CTA scans with Endosize ${ }^{\circledR}$ software. A mesh morphing algorithm based on the work of Grassi et al. (2011) was developed to deform the pre-operative mesh, using centrelines and splines as driving key-points, until obtaining the desired tubular shape surrounding the assembled SG. Nodal displacements from one mesh to the other isotopological mesh could then be computed.

\subsubsection{SG deployment}

The assembled SG was inserted inside the wrapping tubular shell. Its longitudinal position inside the wrapping tube was adjusted to match the longitudinal position of the proximal stent of the main body in simulations and post-operative scans (Figure 6C). This was achieved by (i) measuring on the postoperative scan the distances from the proximal end of the stent-graft to anatomical landmarks placed on the aorta and (ii) positioning the stent-graft inside the tubular shape so that keeping the same distances between the proximal end of the stent-graft and these anatomical landmarks.

For optimal proximal sealing during surgery, practitioners rotate the SG main body to put the lowest parts of the proximal stent right underneath the ostias of renal arteries. To reproduce this procedure, which is specific to Anaconda ${ }^{\mathrm{TM}}$ and the particular saddle shape of its stents, the main body was rigidly rotated inside the wrapping shell until its orientation matched the post-operative scan. Iliac limbs were constrained by contact to stay inside main body stumps during this process.

Afterwards, proper displacements obtained while generating the wrapping shell were prescribed to the nodes of the wrapping shell to morph it back to the pre-operative geometry of the lumen. During this stage, the SG was deformed due to the contact constraint which imposed the SG to fit inside the shell during the whole process. Thereafter, SG modules were deployed in the pre-operative lumen (Figure 6D). Note that while performing this FE analysis, the mechanical properties of the arterial wall were ignored: the wrapping shell was kinematically driven and its final geometry at the end of the morphing stage was stress-free.

For case 1 (in vitro), as the polymer phantom was rigid, pre-operative and post-operative arterial geometries were considered the same. Therefore, the final result of the simulation was obtained at the 
end of the morphing stage. For cases 2 and 3, a supplementary simulation step was performed to compute the final mechanical equilibrium between the SG and the elastic arterial wall, with its proper linearized elastic properties (Figure 6E). Motionless boundary conditions were set the proximal and distal extremities of the aorta and iliac arteries, respectively. The action of the blood pressure onto the wall was not modelled during these simulations as it already existed in the initial geometry. However, the stresses induced by the blood pressure were estimated in order to derive the working point at which the elastic properties of the vessel had to be linearized (see Perrin et al., 2015a for more details).

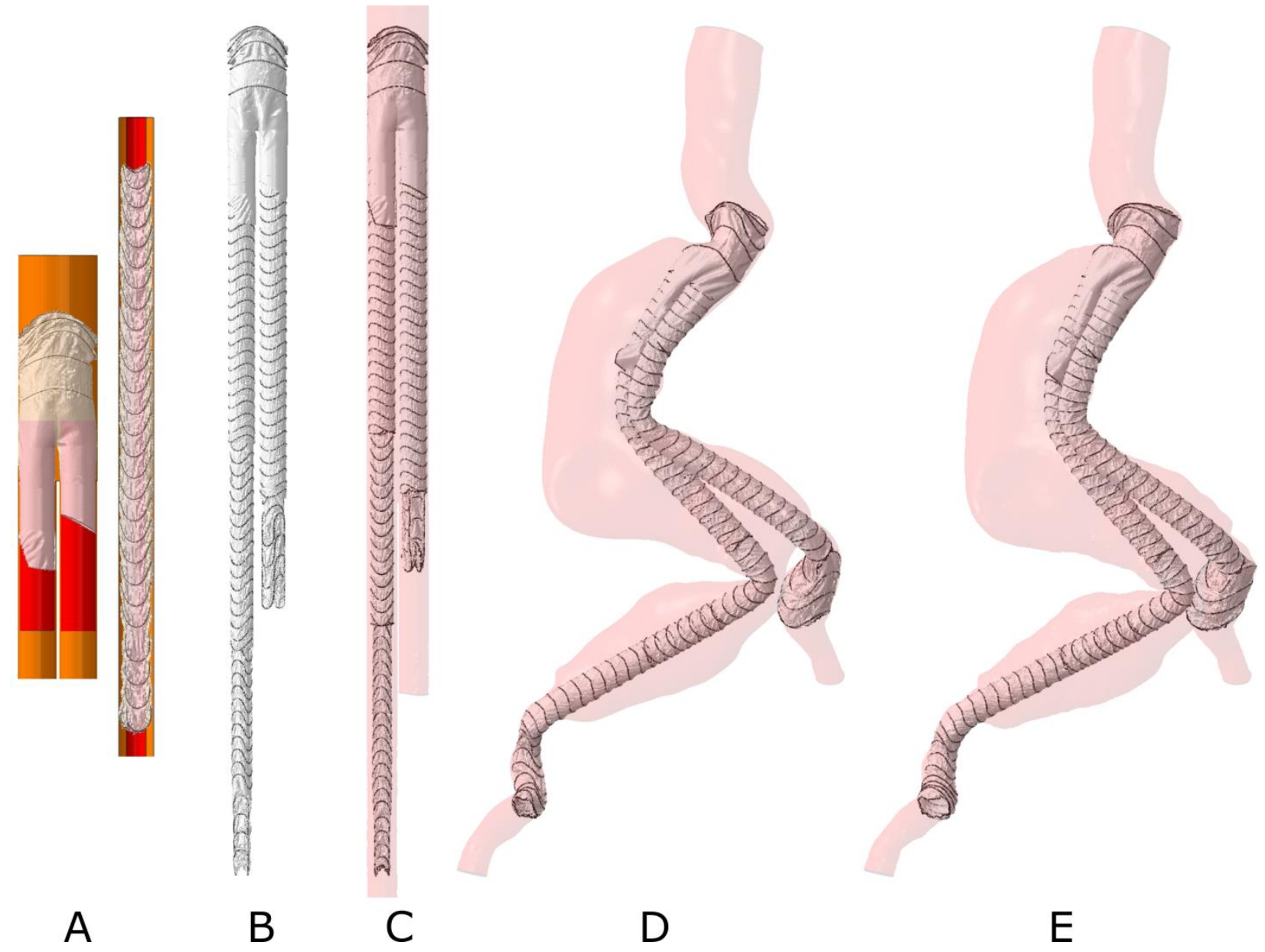

Figure 6. Methodology for numerical SG deployment. Modules crimping (A), SG modules assembly (B), insertion of assembled SG inside the wrapping shell (C), SG deployed in the pre-operative geometry of the arterial lumen (D) and computation of the geometry deformed by the SG for cases 2 and 3 (E).

\subsection{Simulation assessment}

Stent positions in the microtomography scan of the phantom (case 1) or in the post-operative scan (cases 2 and 3) were chosen as reference data to assess the results of the simulations. A first qualitative 
assessment of the results was achieved by superimposing deployed stents geometries of scans and simulations.

A quantitative assessment was also performed for all stents. The iterative closest point method was used to register each stent in the simulations onto its counterpart in the post-operative scans. Each obtained registration matrix was split into a rotation and a translation. The vector defining the position error was derived for each simulated stent as the translation to be applied to register the predicted stent position onto its actual position in the post-operative scan.

Inertia axes were computed for all stents from which longitudinal inertia axes were obtained by detecting the smallest eigenvalue of inertia moments. Position error vector for each pair of simulated/actual stents was then projected onto the longitudinal axis of actual stent. As a result, two components of position error were obtained per simulated stent: (i) a longitudinal position error $e_{L}$, along the stent longitudinal axis and (ii) a transverse position error $e_{T}$, normal to this axis (Figure 7). Stent diameters could also be obtained as the mean distance of the stent centreline to the stent barycentre, in the plane normal to the stent longitudinal axis. A relative diameter error $e_{D}$ for each simulated stent was then computed as the diameter gap between simulations and scans, normalised by the actual stent diameter.

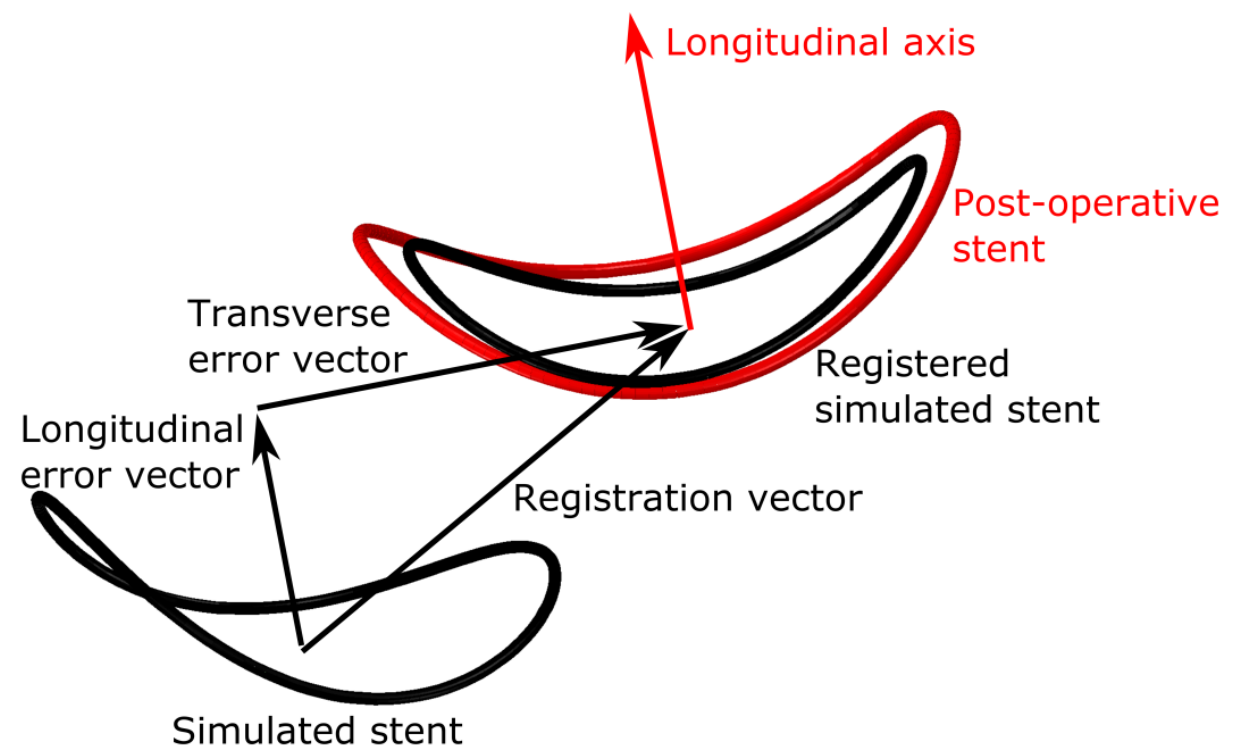

Figure 7. Computation of longitudinal and transverse position errors for each simulated stent. The translation vector, from the simulated stent position to the post-operative stent position, has two components, respectively parallel and perpendicular to the longitudinal axis of the post-operative stent. 


\section{Results}

\subsection{Qualitative assessment}

The comparison of actual and simulated stent positions (Figure 8) shows a very good qualitative agreement.

For the case 1 (in vitro), there is a very good agreement between the simulated stent positions and the tomography scan. Nearly perfect agreement can be noticed in the left iliac limb. In the main body, the orientation of the stents is also very well predicted. The overall SG length, from most proximal to most distal stents, was correctly simulated. The only noticeable discrepancies are located in the aneurysmal sac, where the curvature of the right iliac limb is slightly under predicted.

For case 2, the positions and shapes of the stents of the main body are well reproduced by the simulation. Distal stents of the left iliac extension are deployed at the correct location and have a similar shape as observed on the post-operative CTA scan. However, their deployed orientation is less accurate. The right limbs present the largest discrepancies. Stents are shifted backward and the right iliac artery is not straightened enough by the deployment of the limb compared to the CTA scan. A good agreement was met for case 3 between the simulation and post-operative CTA scan. The main discrepancies are located in the iliac arteries as in the case 2. Both iliac arteries are less straight at the end of the simulation than in the post-operative CTA scan. 

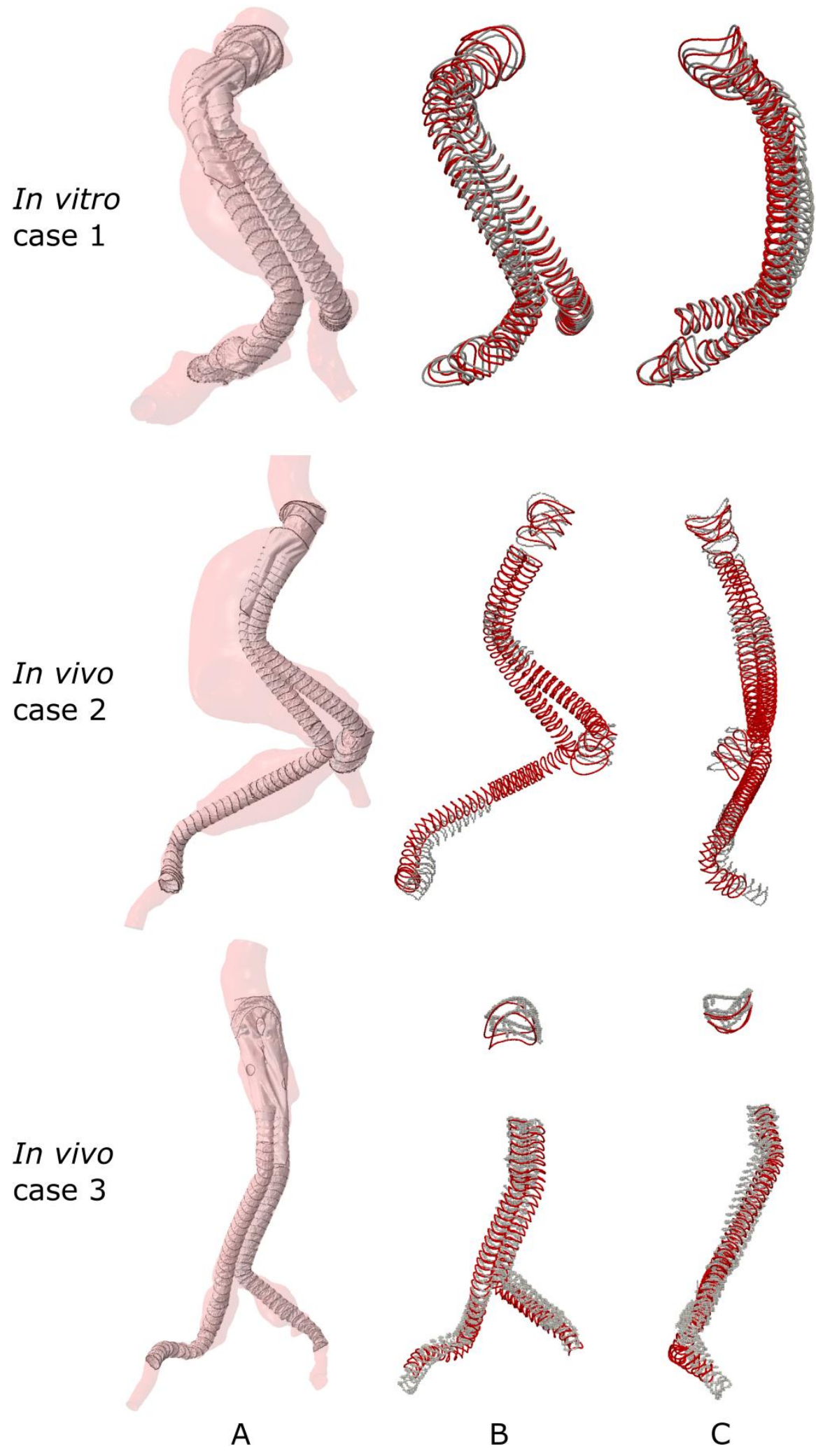

Figure 8. Simulation results for the three cases (A), front view (B) and side view (C) of the qualitative comparison between simulations (red) and scans (grey). 


\subsection{Quantitative assessment}

Stent positions and diameter errors are shown for each individual stent in Figure 9 and globally for all stents in Table 6, for the three cases.

For case 1 (in vitro), absolute values of $e_{L}$ are less than $2 \mathrm{~mm}$ for all the stents of the main body and of the left iliac limb. The right iliac limb and the extension exhibit higher errors, up to $10.6 \mathrm{~mm}$ in the docking zone but less than $4 \mathrm{~mm}$ outside. For all the stents out of overlapping zones, transverse position error $e_{T}$ is less than $3 \mathrm{~mm}$. Maximum $e_{T}$ values, up to $7.1 \mathrm{~mm}$, are located in the aneurysmal sac and in the left stump of the main body. Most stents with $e_{D}>5 \%$ are stents deployed inside another module which may bias the analysis. Accordingly, the largest errors out of docking zones, obtained by excluding overlapping stents are reported in a separate column of Table 6.

For case 2, absolute values of longitudinal position error $e_{L}$ are under $4 \mathrm{~mm}$, except for stents of the right iliac limbs where it rises up to $10.1 \mathrm{~mm}$. The observation is similar for the transverse position error $e_{T}$. Highest values, up to $13.3 \mathrm{~mm}$, are located at the proximal extremity of the right iliac extension whereas it does not exceed $6 \mathrm{~mm}$ everywhere else. Almost all stents have a relative diameter error $e_{D}$ smaller than $10 \%$, the only exception being the four distal stents in the right iliac artery where the maximum error is $16.9 \%$. Similar trends are observed for case 3 : absolute values of $e_{L}$ are less than $5 \mathrm{~mm}$, except for stents of the right iliac extension $\left(14.0 \mathrm{~mm}\right.$ maximum $\left.e_{L}\right)$. Maximum $e_{T}$ value $(10.6 \mathrm{~mm})$ is also located in the right iliac extension but a local maximum rising up to $9.8 \mathrm{~mm}$ can be observed in the aneurysmal sac. Most of the stents present $e_{D}$ values lower than $10 \%$, one stent showing a large error of $36.2 \%$. 

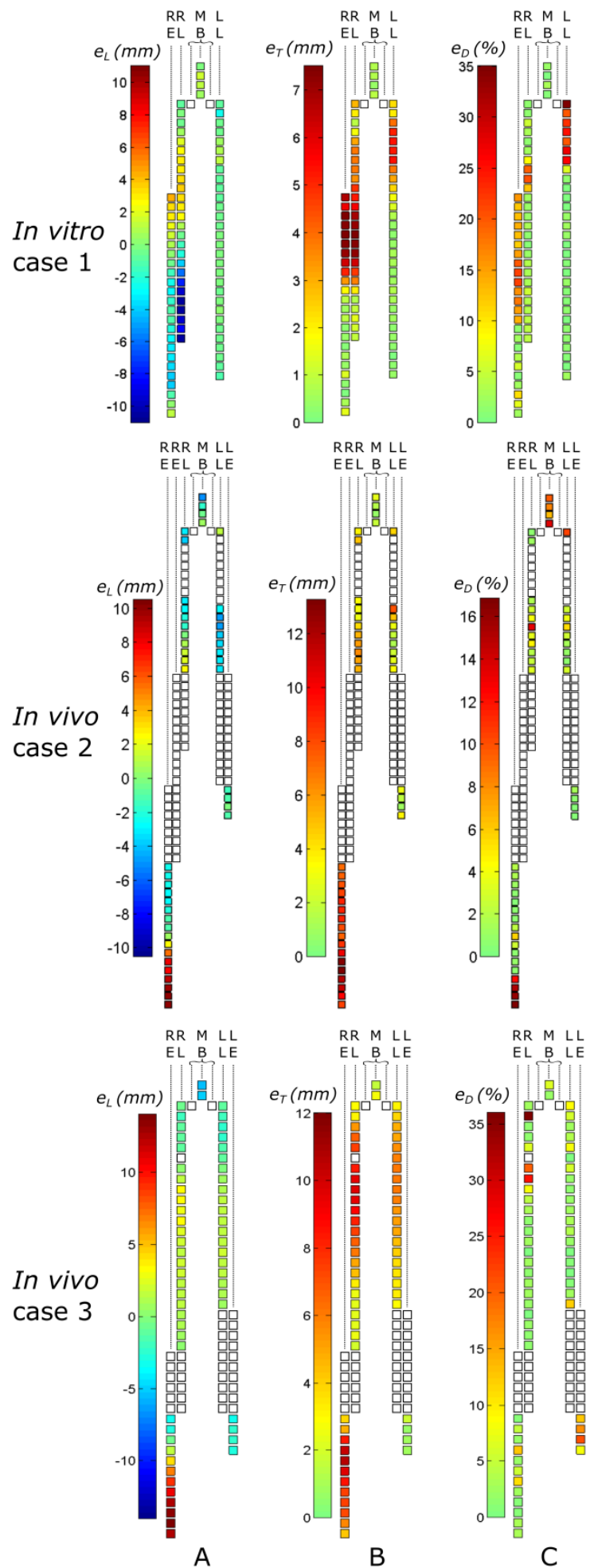

Figure 9. Simulation errors (longitudinal position $e_{L}(\mathrm{~A})$, transverse position $e_{T}(\mathrm{~B})$ and relative diameter $e_{D}(\mathrm{C})$ errors) for each stent of the three cases. The color of each square represents the error value for one stent; columns represent SG modules (RE: right limb extension; RL: right limb; MB: main body with its two stumps; LL: left limb; LE: left limb extension). White squares represent stents which could not be segmented on the post-operative scan and were therefore excluded of the analysis. 


\begin{tabular}{|c|c|c|c|c|}
\hline & $\begin{array}{l}\text { Case } 1 \text { (in } \\
\text { vitro) } \\
\text { All stents } \\
\text { included }\end{array}$ & $\begin{array}{c}\text { Case } 1 \text { (in vitro) } \\
\text { Excluding } \\
\text { overlapping stents }\end{array}$ & $\begin{array}{c}\text { Case } 2 \text { (in vivo) } \\
\text { Excluding } \\
\text { overlapping stents }\end{array}$ & $\begin{array}{c}\text { Case } 3 \text { (in vivo) } \\
\text { Excluding } \\
\text { overlapping stents }\end{array}$ \\
\hline $\begin{array}{l}\qquad e_{L}(\mathrm{~mm}): \\
\text { Mean } \quad \pm \quad \text { standard } \\
\text { deviation } \\
\text { Maximum }\end{array}$ & $\begin{array}{c}-1.0 \pm 3.2 \\
-10.6\end{array}$ & $\begin{array}{c}-0.4 \pm 1.7 \\
-4.1\end{array}$ & $\begin{array}{c}-0.1 \pm 2.1 \\
10.1\end{array}$ & $\begin{array}{c}1.5 \pm 4.2 \\
14.0\end{array}$ \\
\hline $\begin{array}{l}\quad e_{T}(\mathrm{~mm}): \\
\text { Mean } \quad \pm \quad \text { standard } \\
\text { deviation } \\
\text { Maximum }\end{array}$ & $\begin{array}{c}2.5 \pm 2.3 \\
7.1\end{array}$ & $\begin{array}{c}1.0 \pm 1.1 \\
4.5\end{array}$ & $\begin{array}{c}1.4 \pm 3.0 \\
13.3\end{array}$ & $\begin{array}{c}5.2 \pm 2.6 \\
10.6\end{array}$ \\
\hline $\begin{array}{l}\qquad e_{D}(\%): \\
\text { Mean } \quad \pm \quad \text { standard } \\
\text { deviation } \\
\text { Maximum }\end{array}$ & $\begin{array}{c}7.0 \pm 8.2 \\
35.5\end{array}$ & $\begin{array}{c}3.2 \pm 4.9 \\
20.3\end{array}$ & $\begin{array}{c}1.1 \pm 3.0 \\
16.9\end{array}$ & $\begin{array}{c}5.2 \pm 6.7 \\
36.2\end{array}$ \\
\hline
\end{tabular}

Table 6. Mean, standard and maximum errors between simulations and scans.

\section{Discussion}

In this study, we developed computational models of specific SGs, presenting a challenging design. We simulated their deployment inside three patient-specific models of AAAs that were chosen for their complex and tortuous geometries. In the first one, the simulation was compared to the actual position of the SG deployed in vitro in a polymer phantom of the AAA. In the two other cases, the simulations were compared to the actual position of the SG deployed in the AAA of the patients who had an EVAR intervention. A similar simulation methodology was already used successfully in another study (Perrin et al., 2015a), however the present work extends the methodology to a much more challenging SG design and to more complex clinical cases. It highlights the potential of numerical simulation which could eventually help practitioners perform the pre-operative planning of patients. It shows that it is feasible to simulate predictively SG deployment, prior to intervention, even in complex anatomies which are prone to develop post-operative complications and which make SG sizing harder for practitioners. 
As shown by superimposing the simulations and the scans, stents positions are globally well reproduced by the simulations. In case 1 (in vitro), the only visible mismatch was in the aneurysmal sac, where stents were free to move and the lack of constraints did not permit to obtain an agreement as good as in all the other segments of the SG. This observation was confirmed by the quantitative assessment. Apart from overlapping regions which are difficult to analyse, mean $e_{L}$ and $e_{T}$ values were lower than $1.0 \mathrm{~mm}$ and their maximum values were lower than $4.5 \mathrm{~mm}$. These values are small despite the many sources of errors: registration error of pre-operative and post-operative images $(0.8 \mathrm{~mm})$, spatial resolution of the pre-operative CT-scan $\left(0.773 \times 0.773 \times 1.0 \mathrm{~mm}^{3}\right)$, assembly of the two parts of the rigid phantom, transportation of the SG deployed within the phantom from the operating room to the X-ray microtomograph... Furthermore, these error values were below the $5 \mathrm{~mm}$ accuracy threshold which is commonly accepted by practitioners if they want to use simulations in their clinical practice. Indeed, more precision may face two other difficulties: (i) the precision of per-operative SG positioning is still limited to a few millimetres which represent the maximum accuracy reachable using standard intraoperative fluoroscopy and (ii) surgeons often adjust manually the SG position before the deployment by manoeuvring the delivery system and playing with parameters such as the overlap lengths or SG compliance.

One major interest of case 1 (in vitro SG deployment) was that it partly avoided these difficulties and it allowed, thanks to the spatial resolution of X-ray microtomography, to segment with a high resolution the stents in overlapping areas which could not have been obtained otherwise on standard postoperative CTA scans. It could then be observed that $e_{L}, e_{T}$ and $e_{D}$ errors had their maximum values in overlapping regions. Regarding $e_{D}$, diameter overestimations in the proximal stents of the left iliac limb may probably be accounted for by the simplification of the main body stumps in the model. Concerning $e_{L}$ and $e_{T}$, the main sources for the remaining slight errors are: numerous contact with important nonlinearities (edge to edge contact between beam and shell elements), impact of the tie constraint between the textile and the stents, inappropriate friction coefficients which could induce erroneous slippage between overlapping modules and thus produce high $e_{L}$ values.

Overall, the good results and accuracy of SG deployment found in case 1 showed that the Anaconda ${ }^{\mathrm{TM}}$ computational model is able to predict accurately the actual mechanical behaviour of this device, even when complex loads are imposed by the deployment in tortuous arterial geometries. In addition, the simulation methodology was proved to be feasible for such complex clinical cases, by simulating the Anaconda ${ }^{\mathrm{TM}}$ deployment on two other clinical cases. 
Although producing already significant results for the surgical practice, the simulations could still be improved. In the left iliac of case 2 , stents locations and shapes were correctly simulated whereas stents seemed to have two possible orientations to achieve equivalent equilibrium states; the simulation did not lead to the one obtained after surgery. In the right iliac artery of both cases, mismatched positions were observed. Artery straightening, potentially caused by stiff guidewire insertion during actual surgery, was not reproduced and might principally explain such difference. Another reason could be that the position of the patient was not the same during pre-operative and post-operative CTA scans; different leg positions could have affected iliac arteries shapes. Otherwise, the results for both in vivo cases were satisfying given that $87 \%$ out of all stents had absolute $e_{L}$ values lower than $5 \mathrm{~mm}$, which is a clinically relevant accuracy given the spatial resolution of the medical images and the per-operative accuracy of surgeon when deploying SGs. In particular, all the stents of the two main bodies were within this threshold and exhibited $e_{D}$ values lower than $15 \%$, meaning that the simulation accurately reproduced the deployment of the proximal SG extremity, which is a critical zone for surgeons. As observed visually, the remaining $13 \%$ of stents out of this threshold were found in the iliac arteries. In these regions, the high $e_{L}$ values did not reflect that the simulations leaded to inaccurate stent positions relatively to the arterial wall but rather that they resulted in iliac arteries with an inadequate shapes compared to the post-operative CTA scans. Therefore, our methodology could benefit from the simulation of guidewires insertion and induced arterial wall deformations to improve simulation accuracy in iliac arteries (Gindre et al., 2015). In addition, the influence of a more precise modelling of the arterial wall taking into account wall thickness variations, presence of calcifications or intra-luminal thrombus, should be investigated.

The fairly good results gained in this study proved that numerical simulations are able to predict EVAR procedures in complex anatomies with complex flexible SGs. However, additional clinical cases would be required to improve the predictability and reproducibility of the methodology, for a potential clinical use. Among them, it could be interesting to investigate fenestrated SGs, branched SGs or chimney technique, as practitioners could also benefit from the simulation to help them in designing specific SGs to be used in these procedures.

Another possible application of these simulations is the prediction of complications. At the moment, simulation results could be post-processed to estimate luminal areas along the vessel centreline (De Bock et al., 2012; Demanget et al., 2013) and stents apposition defects (De Bock et al., 2014; Perrin et al., 2015b). These estimates could point out possible SG kink, gap between SG and arterial wall or collateral 
artery coverage, and thus potential risk of thrombosis, endoleak or artery occlusion. Additionally, a computer fluid dynamics (CFD) simulation (Kandail et al., 2014), or even a fluid structure interaction (FSI) simulation (Prasad et al., 2013), could be performed after simulating SG deployment to obtain a finer assessment of these complication risks.

Among the challenges to address, reducing the computational cost of present simulation is of first importance. Strongly non-linear mechanical phenomena, like textile wrinkles or multi-body contacts, require highly refined finite element meshes and resolution with an explicit solver. This permits to reach the remarkable precision obtained in the simulations of this study. The downside is that simulations may last more than 40 hours on a 12 cores computer (Intel Xeon, $2.7 \mathrm{GHz}$ ). Such computation time is not compatible with clinical routine. Work is currently in progress to reduce the computation time with model reduction techniques.

\section{Conclusion}

Pre-operative planning of endovascular surgery can become extremely complicated when patients have adverse anatomies, for example tortuous vessels. In such complex cases which are more prone to complications, a predictive tool that could provide information on stent-graft deployment would be helpful for practitioners to confirm patient eligibility and device choice, besides eventually warning for potential post-operative complications. In this study, we have applied a finite-element method to simulate actual deployment of flexible stent-grafts in three patients with tortuous vessels. As proven in this study with a qualitative and quantitative retrospective comparison based on post-operative scans, numerical simulations are robust and accurate enough to predict stent-graft deployment in challenging cases with complex anatomies and highly sophisticated stent-grafts.

\section{Acknowledgements}

The authors would like to acknowledge the Région Rhône-Alpes for the financial support of D. Perrin thesis and the French National Research Agency (ANR) for the funding of Endosim project (grant agreement ANR-13-TECS-0012). The 3SR Lab is part of the LabEx Tec21 (Investissements d'Avenir - grant agreement ANR-11-LABX-0030). The authors would also like to thank the staff of the Gi-Nova platform (Grenoble, France) for their technical support and the company Vascutek for providing stent-graft samples. 


\section{References}

Aburahma, A.F., Campbell, J.E., Mousa, A.Y., Hass, S.M., Stone, P. a., Jain, A., Nanjundappa, A., Dean, L.S., Keiffer, T., Habib, J., 2011. Clinical outcomes for hostile versus favorable aortic neck anatomy in endovascular aortic aneurysm repair using modular devices. Journal of Vascular Surgery 54, 13-21. doi:10.1016/j.jvs.2010.12.010

Albertini, J.N., Perdikides, T., Soong, C. V, Hinchliffe, R.J., Trojanowska, M., Yusuf, S.W., 2006. Endovascular repair of abdominal aortic aneurysms in patients with severe angulation of the proximal neck using a flexible stent-graft: European Multicenter Experience. The Journal of Cardiovascular Surgery 47, 245-250.

Auricchio, F., Conti, M., Marconi, S., Reali, A., Tolenaar, J.L., Trimarchi, S., 2013. Patient-specific aortic endografting simulation: From diagnosis to prediction. Computers in Biology and Medicine 43, 38694. doi:10.1016/j.compbiomed.2013.01.006

Churchill, C.B., Shaw, J.A., ladicola, M.A., 2009. Tips and tricks for characterizing shape memory alloy wire: Part 3-localization and propagation phenomena. Experimental Techniques 33, 70-78. doi:10.1111/j.1747-1567.2009.00558.x

Cochennec, F., Becquemin, J.P., Desgranges, P., Allaire, E., Kobeiter, H., Roudot-Thoraval, F., 2007. Limb graft occlusion following EVAR: Clinical pattern, outcomes and predictive factors of occurrence. European Journal of Vascular and Endovascular Surgery 34, 59-65. doi:10.1016/j.ejvs.2007.01.009

Conway, K.P., Byrne, J., Townsend, M., Lane, I.F., 2001. Prognosis of patients turned down for conventional abdominal aortic aneurysm repair in the endovascular and sonographic era: Szilagyi revisited? Journal of Vascular Surgery 33, 752-757. doi:10.1067/mva.2001.112800

De Bock, S., lannaccone, F., De Beule, M., Van Loo, D., Vermassen, F., Verhegghe, B., Segers, P., 2013. Filling the void: A coalescent numerical and experimental technique to determine aortic stent graft mechanics. Journal of Biomechanics 46, 2477-2482. doi:10.1016/j.jbiomech.2013.07.010

De Bock, S., lannaccone, F., De Beule, M., Vermassen, F., Segers, P., Verhegghe, B., 2014. What if you stretch the IFU? A mechanical insight into stent graft instructions for use in angulated proximal aneurysm necks. Medical Engineering \& Physics. doi:10.1016/j.medengphy.2014.08.003

De Bock, S., lannaccone, F., De Santis, G., De Beule, M., Van Loo, D., Devos, D., Vermassen, F., Segers, P., Verhegghe, B., 2012. Virtual evaluation of stent graft deployment: a validated modeling and simulation study. Journal of the Mechanical Behavior of Biomedical Materials 13, 129-39. doi:10.1016/j.jmbbm.2012.04.021

Demanget, N., Avril, S., Badel, P., Orgéas, L., Geindreau, C., Albertini, J.-N., Favre, J.-P., 2012a. Computational comparison of the bending behavior of aortic stent-grafts. Journal of the Mechanical Behavior of Biomedical Materials 5, 272-282. doi:10.1016/j.jmbbm.2011.09.006

Demanget, N., Duprey, A., Badel, P., Orgéas, L., Avril, S., Geindreau, C., Albertini, J.-N., Favre, J.-P., 2013. Finite Element Analysis of the mechanical performances of 8 marketed aortic stent-grafts. Journal of Endovascular Therapy 20, 523-535. doi:10.1583/12-4063.1

Demanget, N., Latil, P., Orgéas, L., Badel, P., Avril, S., Geindreau, C., Albertini, J.-N., Favre, J.-P., 2012 b. Severe bending of two aortic stent-grafts: An experimental and numerical mechanical analysis. Annals of Biomedical Engineering 40, 2674-2686. doi:10.1007/s10439-012-0618-0

Doube, M., Klosowski, M.M., Arganda-Carreras, I., Cordeli??res, F.P., Dougherty, R.P., Jackson, J.S., 
Schmid, B., Hutchinson, J.R., Shefelbine, S.J., 2010. BoneJ: Free and extensible bone image analysis in ImageJ. Bone 47, 1076-1079. doi:10.1016/j.bone.2010.08.023

Fillinger, M.F., Marra, S.P., Raghavan, M.L., Kennedy, F.E., 2003. Prediction of rupture risk in abdominal aortic aneurysm during observation: Wall stress versus diameter. Journal of Vascular Surgery 37, 724-732. doi:10.1067/mva.2003.213

Gasser, T.C., Ogden, R.W., Holzapfel, G. a, 2006. Hyperelastic modelling of arterial layers with distributed collagen fibre orientations. Journal of the Royal Society 3, 15-35. doi:10.1098/rsif.2005.0073

Gindre, J., Bel-Brunon, A., Combescure, A., Haigron, P., Rochette, M., Lucas, A., 2015. Estimation of clinically relevant indicators for EVAR using patient-specific finite element simulation. Computer Methods in Biomechanics and Biomedical Engineering 1-2. doi:10.1080/10255842.2015.1069552

Grassi, L., Hraiech, N., Schileo, E., Ansaloni, M., Rochette, M., Viceconti, M., 2011. Evaluation of the generality and accuracy of a new mesh morphing procedure for the human femur. Medical Engineering and Physics 33, 112-120. doi:10.1016/j.medengphy.2010.09.014

Greenhalgh, R.M., Brown, L.C., Powell, J.T., Thompson, S.G., Epstein, D., Sculpher, M.J., 2010. Endovascular versus open repair of abdominal aortic aneurysm. The New England journal of medicine 362, 1863-71. doi:10.1056/NEJMoa0909305

Hall, G.J., Kasper, E.P., 2006. Comparison of element technologies for modeling stent expansion. Journal of Biomechanical Engineering 128, 751. doi:10.1115/1.2264382

Henderson, E., Nash, D.H., Dempster, W.M., 2011. On the experimental testing of fine Nitinol wires for medical devices. Journal of the Mechanical Behavior of Biomedical Materials 4, 261-8. doi:10.1016/j.jmbbm.2010.10.004

Kandail, H., Hamady, M., Xu, X.Y., 2014. Patient-specific analysis of displacement forces acting on fenestrated stent grafts for endovascular aneurysm repair. Journal of Biomechanics 47, 3546-3554. doi:10.1016/j.jbiomech.2014.08.011

Kleinstreuer, C., Li, Z., Basciano, C. a, Seelecke, S., Farber, M. a, 2008. Computational mechanics of Nitinol stent grafts. Journal of Biomechanics 41, 2370-8. doi:10.1016/j.jbiomech.2008.05.032

Lee, T.C., Kashyap, R.L., Chu, C.N., 1994. Building skeleton models via 3-D medial surface axis thinning algorithms. CVGIP: Graphical Models and Image Processing 56, 462-478. doi:10.1006/cgip.1994.1042

Perrin, D., Badel, P., Orgéas, L., Geindreau, C., Dumenil, A., Albertini, J.-N., Avril, S., Orgeas, L., Geindreau, C., Dumenil, A., Albertini, J.-N., Avril, S., 2015a. Patient-specific numerical simulation of stent-graft deployment: Validation on three clinical cases. Journal of Biomechanics 48, 1868-1875. doi:10.1016/j.jbiomech.2015.04.031

Perrin, D., Demanget, N., Badel, P., Avril, S., Orgéas, L., Geindreau, C., Albertini, J.-N., 2015b. Deployment of stent grafts in curved aneurysmal arteries: toward a predictive numerical tool. International Journal for Numerical Methods in Biomedical Engineering 31, n/a-n/a. doi:10.1002/cnm.2698

Prasad, A., Xiao, N., Gong, X.-Y., Zarins, C.K., Figueroa, C.A., 2013. A computational framework for investigating the positional stability of aortic endografts. Biomechanics and Modeling in Mechanobiology 12, 869-87. doi:10.1007/s10237-012-0450-3

Sternbergh, W.C., Carter, G., York, J.W., Yoselevitz, M., Money, S.R., 2002. Aortic neck angulation predicts adverse outcome with endovascular abdominal aortic aneurysm repair. Journal of Vascular 
Surgery 35, 482-6. doi:10.1067/mva.2002.119506 